\title{
Does the Risk for Diabetes Related with Alcohol Drinking Depend on Facial Flushing?
}

\author{
Soo Young Kim* \\ Department of Family Medicine, Kangdong Sacred Heart Hospital, Hallym University College of Medicine, Seoul, Korea
}

\section{See original paper on 153}

Approximately $50 \%$ of Koreans have an $A L D H 2$ gene mutation, which can cause facial flushing after alcohol drinking, and it is recently known that various health problems occur in flashers. ${ }^{1)}$ Previous studies have shown that a smaller than usual amount of alcohol intake increased the risk for developing hypertension ${ }^{2)}$ and cardiovascular disease ${ }^{3)}$ in individuals with facial flashing. Furthermore, these individuals may have a greater chance of having risk factors for diabetes, such as metabolic syndrome and insulin resistance. ${ }^{4,5}$ For that reason, it would be reasonable to assume that the risk for diabetes caused by alcohol drinking could also depend on facial flushing.

In the present issue, Kim et al. ${ }^{6)}$ investigated the association between alcohol consumption and the risk for prediabetes or type 2 diabetes mellitus (T2DM) by alcohol-induced flushing response in Korean male adults, particularly based on their body mass index. This study selected 1,030 male adults (158 non-drinkers, 364 flushers, and 508 non-flushers) who had medical checkups and found that when obese non-flushers consumed more than 8 drinks of alcohol on average per week, they had a higher risk for pre- or T2DM than that of nondrinkers. In contrast, it was found that obese flushers had an increased risk for pre- or T2DM even when consuming a relatively low amount of alcohol ( $>4$ drinks/wk).

In light of these results, it can be said that the risk for diabetes increases with obesity and with increase in the amount of alcohol intake, but these risks depend on the presence or absence of facial flashing.
However, this interpretation requires caution. First, it is difficult to clarify that there is a causal relationship between risk for diabetes and facial flushing due to the limitation of the research design (cross-sectional study). Second, it is difficult to generalize the current results because the population of this study was limited to male adults who underwent health checkup in a single institution. However, as a result of several studies, it can be said that a small amount of alcohol intake can increase the risk for several chronic conditions in individuals with facial flushing. Therefore, primary care physicians should ask about facial flushing and provide advise accordingly when talking about health risk factors.

\section{CONFLICT OF INTEREST}

No potential conflict of interest relevant to this article was reported.

\section{ORCID}

Soo Young Kim: https://orcid.org/0000-0002-3205-9408

\section{REFERENCES}

1. Lee S, Kim JS, Jung JG, Oh MK, Chung TH, Kim J. Korean alcohol guidelines for moderate drinking based on facial flushing. Korean J Fam Med 2019;40:204-11.

2. Jung JG, Kim JS, Kim YS, Oh MK, Yoon SJ. Hypertension associated with alcohol consumption based on the facial flushing reaction to drinking. Alcohol Clin Exp Res 2014;38:1020-5. 
3. Suh HS, Kim JS, Kim SS, Jung JG, Yoon SJ, Ahn JB. Influence of the flushing response in the relationship between alcohol consumption and cardiovascular disease risk. Korean J Fam Med 2014;35:295-302.

4. Seo YR, Kim JS, Kim SS, Jung JG, Yoon SJ. Association between alcohol consumption and metabolic syndrome determined by facial flushing in Korean women. Korean J Fam Med 2020 Feb 14 [Epub]. https://doi. org/10.4082/kjfm.19.0141.
5. Jung JG, Kim JS, Oh MK. The role of the flushing response in the relationship between alcohol consumption and insulin resistance. Alcohol Clin Exp Res 2010;34:1699-704.

6. Kim J, Kim JS, Kim SS, Jung JG, Yoon SJ, Seo YR, et al. Influence of facial flushing on pre- or type 2 diabetes risk according to alcohol consumption in Korean male. Korean J Fam Med 2020;41:153-60. 